\title{
Dioscin inhibits SCC15 cell proliferation via the RASSF1A/MST2/YAP axis
}

\author{
HUI TIAN ${ }^{1,2 *}$, XIYAN CHEN $^{1-3^{*}}$, YAFEI ZHANG ${ }^{1,2}$, YING WANG $^{1,2}$, \\ XUCHENG FU ${ }^{1,2}$, WEITING GU ${ }^{4}$ and YONG WEN ${ }^{1,2}$ \\ ${ }^{1}$ Department of Implantology, School and Hospital of Stomatology, Cheeloo College of Medicine, Shandong University; \\ ${ }^{2}$ Shandong Key Laboratory of Oral Tissue Regeneration, Shandong Engineering Laboratory for Dental Materials and \\ Oral Tissue Regeneration, Jinan, Shandong 250012; ${ }^{3}$ Department of Stomatology, The Sixth Affiliated Hospital of \\ Sun Yat-sen University, Guangzhou, Guangdong 510000; ${ }^{4}$ Department of Obstetrics and Gynecology, \\ Qilu Hospital of Shandong University, Jinan, Shandong 250012, P.R. China
}

Received December 4, 2019; Accepted February 25, 2021

DOI: $10.3892 / \mathrm{mmr} .2021 .12053$

\begin{abstract}
Dioscin, an extract from traditional Chinese herbal plants, displays various biological and pharmacological effects on tumors, including inhibition of cell proliferation and induction of DNA damage. However, the effects of dioscin on oral squamous cell carcinoma (OSCC) cells are not completely understood. The present study aimed to evaluate the impact of dioscin on OSCC cell proliferation. Cell Counting Kit-8 and 5-ethynyl-2'-deoxyuridine incorporation assays were performed to assess cell proliferation. Flow cytometry was conducted to detect alterations in the cell cycle and cell apoptosis. Western blotting and coimmunoprecipitation were performed to determine protein expression levels. In SCC15 cells, dioscin treatment significantly induced cell cycle arrest, increased apoptosis and inhibited proliferation compared with the control group. Mechanistically, the tumor suppressor protein Ras association domain-containing protein $1 \mathrm{~A}$ (RASSF1A) was activated and oncoprotein yes-associated protein (YAP) was phosphorylated by dioscin. Furthermore, YAP overexpression and knockdown reduced and enhanced the inhibitory effects of dioscin on SCC15 cells, respectively. In summary, the results demonstrated that, compared with
\end{abstract}

Correspondence to: Professor Yong Wen, Department of Implantology, School and Hospital of Stomatology, Cheeloo College of Medicine, Shandong University, 44-1 Wenhua Road West, Jinan, Shandong 250012, P.R. China

E-mail: wenyong@sdu.edu.cn

Dr Weiting Gu, Department of Obstetrics and Gynecology, Qilu Hospital of Shandong University, 107 Wenhua Xi Road, Jinan, Shandong 250012, P.R. China

E-mail: weitinggu@gmail.com

${ }^{*}$ Contributed equally

Key words: dioscin, yes-associated protein, Ras association domain-containing protein $1 \mathrm{~A}$, proliferation the control group, dioscin upregulated RASSF1A expression in OSCC cells, which resulted in YAP phosphorylation, thus weakening its transcriptional coactivation function, enhancing cell cycle arrest and apoptosis, and inhibiting cell proliferation. The present study indicated that dioscin may serve as a therapeutic agent for OSCC.

\section{Introduction}

Oral squamous cell carcinoma (OSCC) is a common oral disease. According to the most recent GLOBOCAN estimate, in Europe between 2012 and 2015, there was an overall increasing incidence of oral cancer and of oral cancer-associated mortality $(1,2)$. At present, OSCC treatment regimens include a combination of surgery, radiotherapy and chemotherapy $(3,4)$. Despite the rapid development of modern medicine, the cure rate for OSCC is still poor, displaying an overall 5-year survival rate of $60 \%$ (5). Therefore, identifying additional safe and effective targeted drugs with low cytotoxicity is important.

It has been reported that natural plant products display tumor-inhibitory activities when used as chemopreventive or therapeutic agents against human cancer cells $(6,7)$. Dioscin, which is extracted from the traditional Chinese medicinal herb Dioscorea nipponica, has been reported to display various biological effects, including renal ischemia/reperfusion injury-alleviating, anti-inflammatory and antiallergic effects $(8,9)$. Additionally, in a nephrotoxicity and cardiotoxicity model, dioscin displayed protective effects via regulating oxidative stress (10-12). Meanwhile, dioscin has been reported to display potent effects against different types of cancer. For example, dioscin markedly inhibited hepatocellular carcinoma proliferation and migration, but induced apoptosis, autophagy and DNA damage (13). Si et al (14) reported that dioscin suppressed laryngeal cancer cell proliferation via inducing cell cycle arrest and inhibiting tumor invasion. Furthermore, dioscin inhibited human lung cancer cell proliferation (15). However, to the best of our knowledge, the effect of dioscin on OSCC has not been previously reported.

The Hippo signaling pathway is highly conserved across species. In mammals, the macrophage stimulating 
(MST)1/MST2 kinases can form a complex with salvador family WW domain containing protein 1 and activate the downstream kinases large tumor suppressor kinase (LATS)1 and LATS2 (16). One protein substrate of LATS is yes-associated protein (YAP), which is an important effector protein in the Hippo signaling pathway (17). Phosphorylated (p)-YAP is sequestered in the cytoplasm, preventing its transcriptional activation activity (18). Ras association domain-containing protein 1 (RASSF1), a tumor suppressor gene located on chromosome 3p21, is inactivated in numerous types of cancer (19). Several protein subtypes can be expressed from the RASSF1 gene via alternative splicing and promoter usage, the predominant forms are RASSF1A and RASSF1C, which have different N-termini (20). In a previous study, dioscin induced RASSF1 demethylation in bladder cancer (21).

The aforementioned studies indicated that dioscin may regulate the bioactivity of OSCC cells, which may involve the Hippo/YAP signaling pathway. Therefore, the present study aimed to evaluate the biological effects of dioscin on OSCC cells, as well as the possible underlying effects. The results of the present study suggested that dioscin may serve as a therapeutic agent for OSCC.

\section{Materials and methods}

Cell line and culture. The tongue squamous cell line SCC15 was provided by Professor Shaohua Liu (Qilu Hospital of Shandong University, Jinan, China). SCC15 cells were cultured in DMEM (HyClone; Cytiva) supplemented with $10 \% \mathrm{FBS}$ (Gibco; Thermo Fisher Scientific, Inc.) at $37^{\circ} \mathrm{C}$ with $5 \% \mathrm{CO}_{2}$.

Reagents and antibodies. Dioscin (purity $\geq 98 \%$ ) was purchased from Beijing Solarbio Science \& Technology Co., Ltd. Cells were treated with different concentrations of dioscin $(0,0.5,1$ or $2 \mu \mathrm{M})$ for 24 or $48 \mathrm{~h}$, or with $1 \mu \mathrm{M}$ dioscin for different durations (0, 2, 4 or 8 h). Nuclear Protein Extraction kit (cat. no. R0050) was purchased from Beijing Solarbio Science \& Technology Co., Ltd and was used to extract nuclear proteins prior to western blotting. Primary antibodies targeted against GAPDH (cat. no. 60004-1-Ig) and histone H3 (cat. no. 17168-1-AP) were obtained from ProteinTech Group, Inc. Primary antibodies targeted against LATS1 (cat. no. 3477), p-LATS1 (Ser909; cat. no. 9157), p-MST (cat. no. 49332), MST2 (cat. no. 3952), YAP (cat. no. 4912), p-YAP (Ser397; cat. no. 13619), cyclin D1 (cat. no. 92G2) and BAX (cat. no. 5023) were purchased from Cell Signaling Technologies, Inc. The primary antibody targeted against BCL-2 (cat. no. WL01556) was purchased from Wanleibio Co., Ltd. The primary antibody targeted against RASSF1A (cat. no. ab91212) was purchased from Abcam. The goat anti-mouse or anti-rabbit HRP-conjugated secondary antibody (cat. nos. S0002 or S0001) was obtained from Affinity Biosciences.

Western blotting. After washing twice with ice-cold PBS, the total protein in cells were lysed using RIPA (cat. no. R0020; Beijing Solarbio Science \& Technology Co., Ltd.) lysis buffer for $30 \mathrm{~min}$ on ice. Cells were harvested and centrifuged at $20,664 \times \mathrm{g}$ at $4^{\circ} \mathrm{C}$ for $15 \mathrm{~min}$. In order to extract nuclear protein from the cells, cells were lysed using cytoplasmic protein extraction reagent lysis buffer for $30 \mathrm{~min}$ on ice. The proteins were collected from the supernatant after centrifugation at $20,664 \mathrm{x} \mathrm{g}$ at $4^{\circ} \mathrm{C}$ for $15 \mathrm{~min}$, and the nuclear protein extraction reagent was added to the cell precipitation for centrifugation at $20,664 \mathrm{x} \mathrm{g}$ at $4^{\circ} \mathrm{C}$ for $15 \mathrm{~min}$ and collection of nuclear protein. Protein concentrations were determined using a BCA protein assay. Subsequently, proteins $(20 \mu \mathrm{g})$ were separated via SDS-PAGE on $10 \%$ gels and transferred to PVDF membranes (EMD Millipore). After blocking with non-fat milk for $1 \mathrm{~h}$ at room temperature, the membranes were incubated overnight at $4^{\circ} \mathrm{C}$ with the appropriate primary antibodies (all 1:1,000). After washing three times with TBS-0.1\% Tween-20 (TBST) for $15 \mathrm{~min}$ per wash, the membranes were incubated with a goat anti-mouse or anti-rabbit HRP-conjugated secondary antibody (1:20,000) for $1 \mathrm{~h}$ at room temperature. The membranes were washed three times with TBST and then protein bands were visualized using an enhanced chemiluminescence kit (EMD Millipore) under using an Imager 600 (Amersham; Cytiva). GAPDH and histone $\mathrm{H} 3$ were used as the loading controls. Protein expression levels were analyzed by ImageJ (1.8.0) software (National Institutes of Health).

Coimmunoprecipitation. Following treatment with dioscin for $24 \mathrm{~h}$, lysates were prepared according to the manufacturer's instructions (Active Motif, Inc.). Following centrifugation at $4^{\circ} \mathrm{C}$ for $5 \mathrm{~min}$ at $137 \mathrm{x} \mathrm{g}$, cells were suspended in $100 \mu$ l freshly prepared complete RIPA buffer and incubated for $30 \mathrm{~min}$ on a rotating platform at $4^{\circ} \mathrm{C}$. Whole cell extract was combined with $5 \mu \mathrm{g} \mathrm{IgG} \mathrm{(cat.} \mathrm{no.} \mathrm{3900)} \mathrm{or} \mathrm{anti-MST2} \mathrm{(cat.} \mathrm{no.} \mathrm{3952)}$ antibodies (both from Cell Signaling Technology, Inc.) in a final volume of $500 \mu \mathrm{l}$ and incubated overnight at $4^{\circ} \mathrm{C}$ on a rotating platform. Subsequently, $25 \mu \mathrm{l}$ protein $\mathrm{G}$ magnetic beads were added to the tube and incubated overnight at $4^{\circ} \mathrm{C}$ on a rotating platform. The protein $\mathrm{G}$ magnetic beads were washed carefully and the protein samples were obtained. The samples were resuspended in loading buffer (cat. no. P1040; Beijing Solarbio Science \& Technology Co., Ltd.) and boiled for subsequent analysis via western blotting, according to the aforementioned protocol.

Cell proliferation. Cell proliferation was assessed by performing Cell Counting Kit-8 (CCK-8) assays (Dojindo Molecular Technologies, Inc.) according to the manufacturer's protocol. SCC15 cells $\left(3 \times 10^{3}\right.$ cells/well) were seeded into a 96-well plate. After treatment, cells were cultured for 1-4 days. Subsequently, $10 \mu$ l CCK-8 solution was added to each well with $100 \mu \mathrm{l}$ DMEM and incubated for $2 \mathrm{~h}$ at $37^{\circ} \mathrm{C}$. Optical density values were measured at a wavelength of $450 \mathrm{~nm}$.

5-Ethynyl-2'-deoxyuridine (EdU) proliferation assay. Cells (1x10 $/$ well) were seeded into a 48 -well plate and cultured for $48 \mathrm{~h}$. The EdU Apollo DNA in vitro Kit (Guangzhou RiboBio Co., Ltd.) was used to assess cell proliferation. Cells were cultured with $200 \mu \mathrm{l}$ EdU for $2 \mathrm{~h}$ and were then fixed with $4 \%$ paraformaldehyde for $30 \mathrm{~min}$ at room temperature. Subsequently, cells were treated for $10 \mathrm{~min}$ with $2 \mathrm{mg} / \mathrm{ml}$ glycine and $0.5 \%$ Triton $\mathrm{X}-100$ at room temperature. Then, DAPI working solution was added to each well and incubated for $30 \mathrm{~min}$ in the dark at room temperature. Quantification 
of $\mathrm{EdU}^{+}$cells was expressed as a percentage of $\mathrm{DAPI}^{+}$cells. The percentage of EdU ${ }^{+}$cells was determined by fluorescence microscopy (Olympus Corporation).

Lentiviral ( $L V)$ transduction. cells ( $1 \times 10^{5} /$ well) were seeded into a 6-well plate and cultured for $24 \mathrm{~h}$. At $~ 70 \%$ confluence, SCC15 cells were transduced with LV-homo-YAP particles [overexpression (OE) YAP group] or LV-5-negative control (NC; empty vector; OE NC group) for $12 \mathrm{~h}$. Similarly, SCC15 cells were transduced with LV-homo-YAP-short hairpin (sh) RNA LV particles (sh YAP group) or a corresponding empty $\mathrm{LV}$ vector (sh NC group) for $12 \mathrm{~h}$. The MOI for transduction was 20. All LV particles were purchased from Shanghai Genepharma Co., Ltd. After transduction for 48 h, cells were treated with $1 \mu \mathrm{g} / \mathrm{ml}$ puromycin for 2 weeks. Transduction efficiency was assessed via western blotting.

Flow cytometric analysis of the cell cycle. Cells $\left(1 \times 10^{6}\right)$ were harvested, fixed in $75 \%$ ethanol overnight at $4^{\circ} \mathrm{C}$, washed with cold PBS and incubated with $0.5 \mathrm{ml}$ propidium iodide/RNase (Tianjin Sungene Biotech Co., Ltd.) working solution for $30 \mathrm{~min}$ at room temperature. Subsequently, the cell cycle distribution was determined using an Accuri C6 flow cytometer (Becton, Dickinson and Company) and analyzed using FlowJo software (version 10; FlowJo LLC).

Flow cytometric analysis of cell apoptosis. The Annexin V-PI staining kit was used to assess apoptosis [Multi Sciences (Lianke) Biotech Co., Ltd.]. Cells were harvested, washed with cold PBS and suspended in $500 \mu$ l binding buffer. Subsequently, cells were incubated with $5 \mu \mathrm{l}$ Annexin-V allophycocyanin working solution for $10 \mathrm{~min}$ in the dark at room temperature. Then, cells were incubated with $5 \mu 1$ 7-aminoactinomycin D working solution for $5 \mathrm{~min}$ in the dark at room temperature. Within $1 \mathrm{~h}$, early and late cell apoptosis was determined using an Accuri C6 flow cytometer (Becton, Dickinson and Company) and analyzed using FlowJo software (version 10; FlowJo, LLC).

Statistical analysis. Data are presented as the mean \pm SD of three independent experiments. Statistical analyses were performed using GraphPad Prism software (version 6; GraphPad Software, Inc.). Comparisons among multiple groups were analyzed using one-way ANOVA followed by Tukey's post hoc test. $\mathrm{P}<0.05$ was considered to indicate a statistically significant difference.

\section{Results}

Dioscin reduces SCC15 cell proliferation. To investigate the effects of dioscin on proliferation, SCC15 cells were treated with different concentrations of dioscin for 24 or $48 \mathrm{~h}$, and cell proliferation was determined by performing CCK- 8 assays. Compared with the control group $(1.014 \pm 0.026)$, dioscin treatment significantly inhibited cell proliferation, even at $0.5 \mu \mathrm{M}$ $(0.820 \pm 0.004)$ (Fig. 1A). Similar results were obtained following treatment for $48 \mathrm{~h}$ (Fig. 1B). Moreover, the EdU incorporation assay results indicated that dioscin significantly decreased the ratio of EdU ${ }^{+}$cells in a concentration-dependent manner $(31.150 \pm 0.382,22.92 \pm 0.352$ and $18.100 \pm 0.311 \%$ at
0.5, 1 and $2 \mu \mathrm{M}$, respectively) compared with the control group $(41.410 \pm 0.813 \%)$ (Fig. 1C and D). The results indicated that dioscin inhibited SCC15 cell proliferation in a dose-dependent manner.

Dioscin induces SCC15 cell cycle arrest and apoptosis. To explore the cellular mechanism underlying the antiproliferative effect of dioscin on SCC15 cells, flow cytometry was performed to detect alterations in the cell cycle and apoptosis. Following treatment with $0.5,1$ or $2 \mu \mathrm{M}$ dioscin, the number of cells in the $G_{2} / M$ phase was significantly decreased $(5.663 \pm 0.350$, $1.816 \pm 0.304$ and $0.5667 \pm 0.173 \%$, respectively) compared with the control group $(7.283 \pm 0.238 \%$ ) (Fig. 2A and B). Moreover, following treatment with 1 or $2 \mu \mathrm{M}$ dioscin, the number of cells in the $\mathrm{G}_{0} / \mathrm{G}_{1}$ phase was significantly increased $(69.740 \pm 1.3960$ and $74.200 \pm 0.305 \%$, respectively) compared with the control group $(65.830 \pm 0.644 \%)$. Subsequently, the effect of dioscin on cell apoptosis was evaluated. Compared with the control group (early apoptosis, 2.464 $\pm 0.110 \%$; late apoptosis, $6.254 \pm 0.078 \%)$, dioscin $(0.5,1$ or $2 \mu \mathrm{M})$ significantly increased the population of early $(3.100 \pm 0.112$, $5.624 \pm 0.248$ and $7.790 \pm 0.330 \%$, respectively) and late $(8.142 \pm 0.072,15.100 \pm 0.353$ and $21.020 \pm 0.213 \%$, respectively) apoptotic cells (Fig. 2C and D). The apoptosis-inducing effect of dioscin was enhanced with increasing concentrations.

Dioscin-induced inhibition of cell proliferation is mediated by the Hippo signaling pathway. Previous research has demonstrated that RASSF1 supports the phosphorylation of MST2 and SAV, both of which are upstream molecules of YAP (22). A previous study reported that dioscin induced RASSF1 demethylation and inhibited the proliferative activity of bladder cancer cell lines (21). Therefore, the present study aimed to investigate the role of the Hippo signaling pathway in dioscin-treated cells. SCC15 cells were treated with different concentrations of dioscin $(0,0.5,1$ or $2 \mu \mathrm{M})$ for $24 \mathrm{~h}$ or with $1 \mu \mathrm{M}$ dioscin for different durations $(0,2,4$ or $8 \mathrm{~h})$. The ratios of $\mathrm{p}$-LATS (Ser909)/LATS, p-MST/MST2 and p-YAP (Ser397)/YAP were significantly increased by dioscin treatment in a concentrationand time-dependent manner compared with the control group (Fig. 3A-D). Compared with the control group, dioscin did not notably alter the expression levels of total LATS1 and MST2, but markedly decreased the expression levels of total YAP (Fig. 3A-D). In addition, the expression levels of cell cycleand apoptosis-related proteins were assessed. Cyclin D1 and BCL-2 expression levels were markedly decreased by dioscin in a concentration- and time-dependent manner compared with the control group (Fig. 3E and F). However, BAX expression levels displayed the opposite pattern. To investigate whether dioscin treatment altered the localization of YAP, nuclear and cytoplasmic proteins were extracted using the Nuclear Protein Extraction kit. As dioscin concentrations increased, nuclear YAP expression levels were markedly decreased, whereas YAP cytoplasmic accumulation was notably increased compared with the control group (Fig. 3G).

To detect Hippo signaling pathway activation following dioscin treatment, the expression levels of RASSF1A, a protein consistently linked to tumor onset and poor cancer prognosis (23), were detected. The western blotting results indicated that RASSF1A expression levels were markedly increased 
A

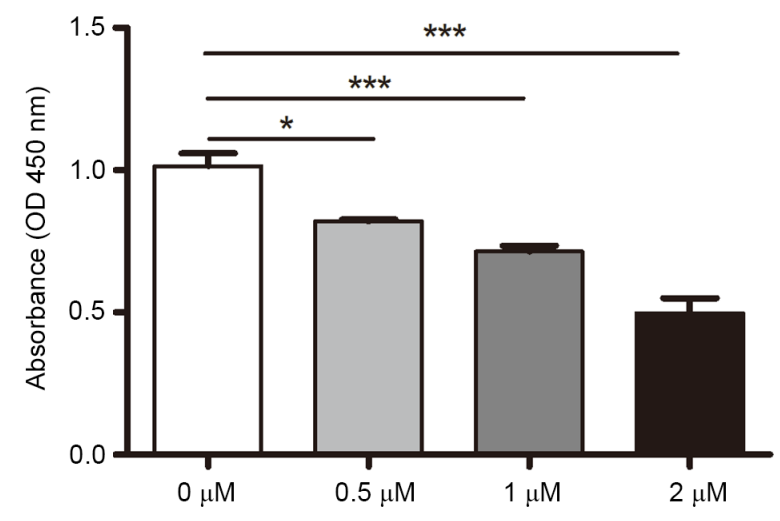

C

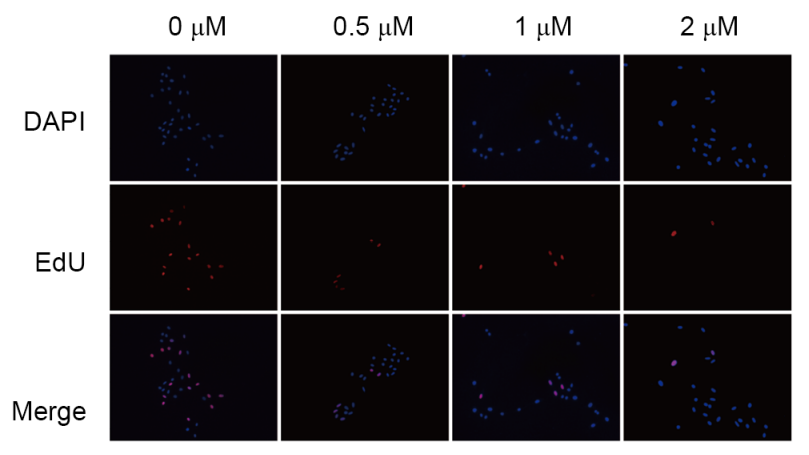

B

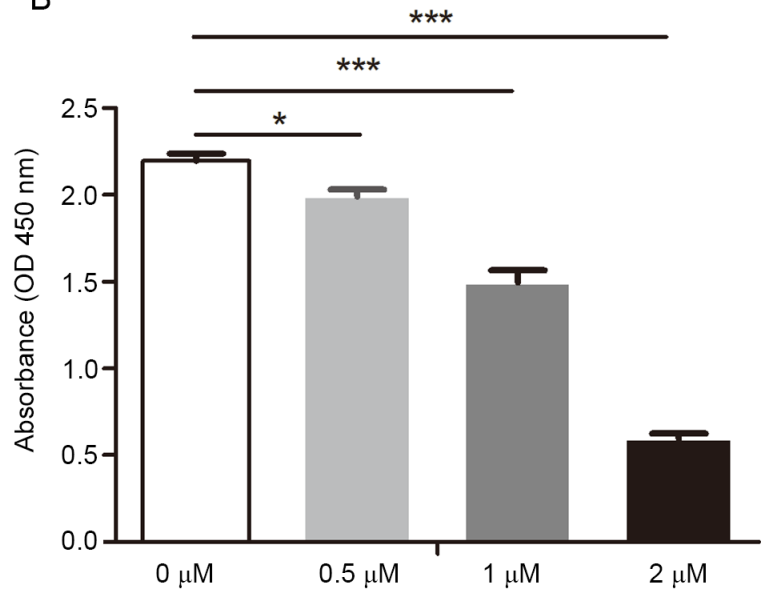

D

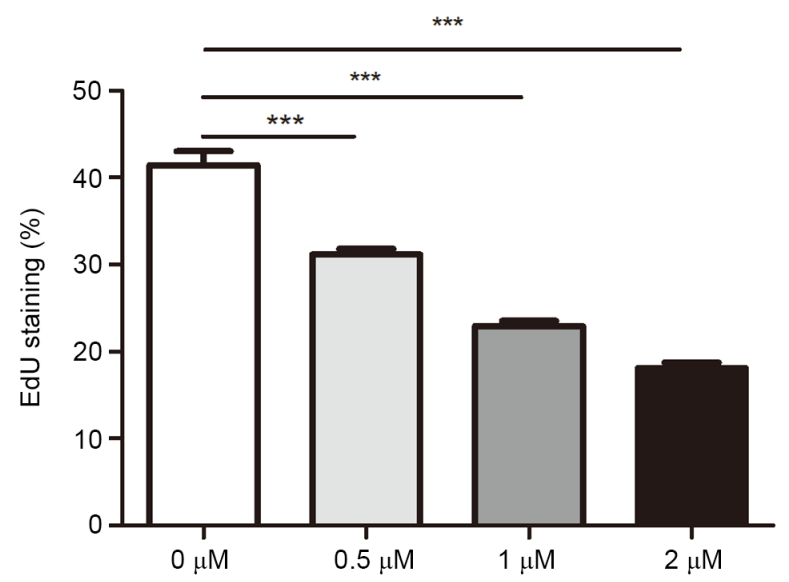

Figure 1. Dioscin inhibits SCC15 cell proliferation. SCC15 cell proliferation following treatment with $0,0.5,1$ or $2 \mu \mathrm{M}$ dioscin for (A) 24 or (B) $48 \mathrm{~h}$ was determined by performing Cell Counting Kit-8 assays. (C) SCC15 cells were treated with 0, 0.5, 1 or $2 \mu \mathrm{M}$ dioscin and EdU staining was performed (magnification, $\mathrm{x} 200$ ). (D) Quantification of EdU ${ }^{+}$cells expressed as a percentage of $\mathrm{DAPI}^{+}$cells. Data are presented as the mean \pm SD of three independent experiments. ${ }^{*} \mathrm{P}<0.05$ and ${ }^{* * *} \mathrm{P}<0.001$. OD, optical density; EdU, 5-ethynyl-2'-deoxyuridine.

by dioscin treatment in a concentration- and time-dependent manner compared with the control group (Fig. 3A and B). However, the mechanism underlying dioscin-induced inactivation of the Hippo signaling pathway is not completely understood. RASSF1A has been reported to form a complex with MST2 and SAV, which phosphorylates LATS1, leading to YAP phosphorylation (24). The aforementioned results indicated that dioscin treatment resulted in RASSF1A accumulation (Fig. 3A and B), and endogenous RASSF1Aor LATS1 were coimmunoprecipitated with the MST2protein (Fig. 3H). As shown in Fig. 3H, RASSF1A and LATS1 were detected in the anti-MST2 precipitate, but not in the $\mathrm{IgG}$ precipitate.

YAP overexpression abrogates dioscin-induced inhibition of cell proliferation. The aforementioned results indicated that the RASSF1A/MST2/YAP axis was involved in dioscin-induced inhibition of cell proliferation. To evaluate the hypothesis, SCC15 cells were transduced with OE YAP or OE NC and then treated with $1 \mu \mathrm{M}$ dioscin. The flow cytometry results demonstrated that, compared with the OE NC group $(3.450 \pm 0.886 \%)$, dioscin treatment significantly decreased the number of cells in the $\mathrm{G}_{2} / \mathrm{M}$ phase $(1.097 \pm 0.112 \%)$, whereas the number of cells in the proliferative phases was significantly increased in the OE YAP group $(7.887 \pm 0.206 \%)$ compared with the OE NC group. (Fig. 4A and B). Meanwhile, compared with the $\mathrm{OE} \mathrm{NC}+$ dioscin group $(1.097 \pm 0.112 \%)$, the increase of proliferation activity of OE YAP + dioscin group $(6.890 \pm 0.237 \%)$, indicated that overexpression of YAP gene abrogated dioscin-induced inhibition of cell proliferation. (Fig. 4B). The apoptosis assay results demonstrated that dioscin treatment significantly increased the number of apoptotic cells $(39.010 \pm 0.464 \%)$, whereas in the OE YAP group this increase was attenuated $(19.150 \pm 0.831 \%)$ compared with the OE NC group (24.770 $\pm 0.382 \%$ ) (Fig. $4 \mathrm{C}$ and D). The EdU incorporation (Fig. 4E and F) and CCK-8 (Fig. 4G) assay results demonstrated that, compared with the OE NC group or OE YAP group, dioscin treatment significantly suppressed SCC15 cell proliferation in the $\mathrm{OE} \mathrm{NC}+$ dioscin and OE YAP + dioscin groups, whereas YAP overexpression in the OE YAP or OE YAP + dioscin groups enhanced cell proliferation compared with the $\mathrm{OE} \mathrm{NC}$ or $\mathrm{OE} \mathrm{NC} \mathrm{+} \mathrm{dioscin} \mathrm{groups,}$ respectively. The dioscin-induced suppression of proliferation 
A
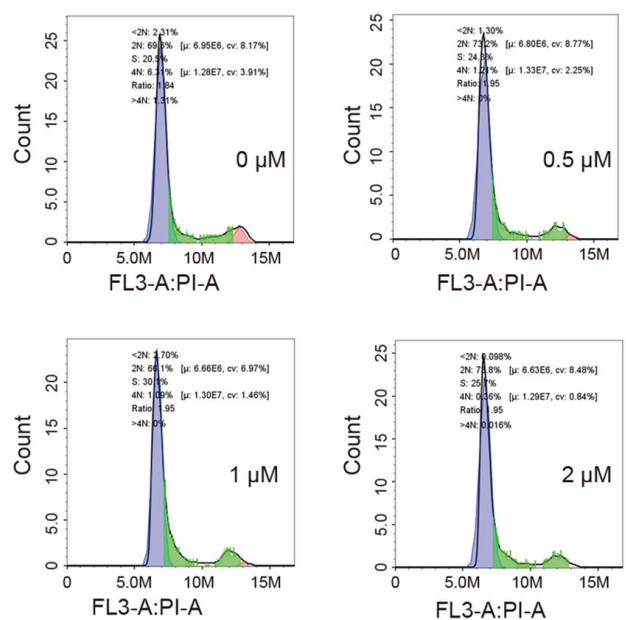

C
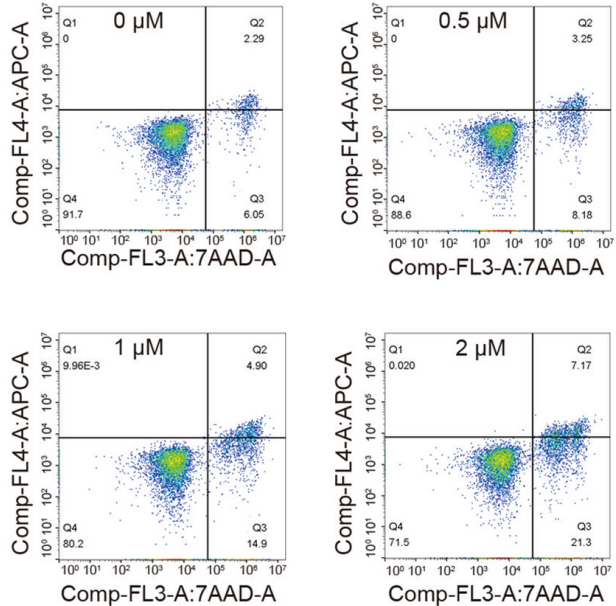

B

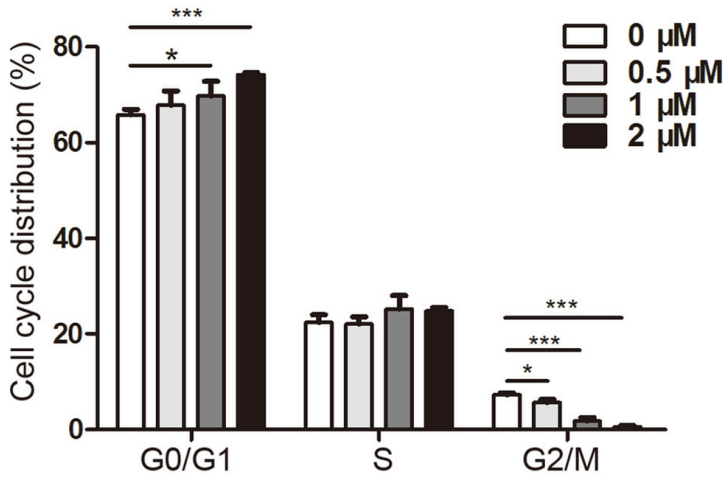

D

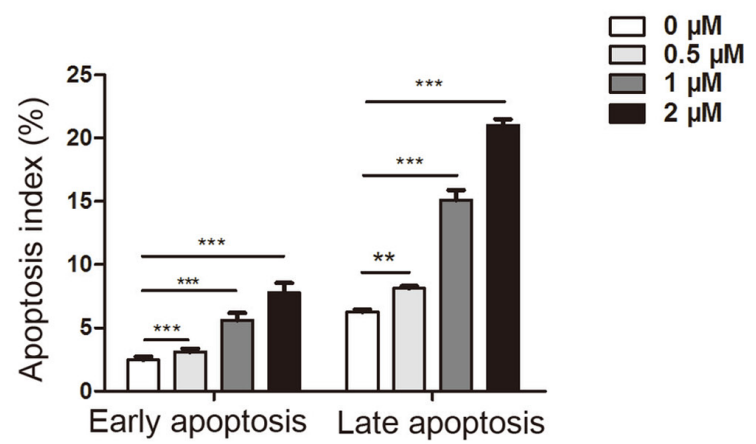

Figure 2. Dioscin induces SCC15 cell cycle arrest and apoptosis. Effects of different doses of dioscin on the cell cycle distribution were (A) determined via flow cytometry and (B) quantified $(n=3)$. Effects of different doses of dioscin on early and late cell apoptosis were $(C)$ determined via flow cytometry and (D) quantified $(\mathrm{n}=5)$. Data are presented as the mean $\pm \mathrm{SD} .{ }^{*} \mathrm{P}<0.05,{ }^{* *} \mathrm{P}<0.01$ and ${ }^{* * *} \mathrm{P}<0.001$. APC, allophycocyanin.

was inhibited in the OE YAP group. The protein expression levels of cell cycle- and apoptosis-related proteins were measured via western blotting. The western blotting results further verified the alterations in the cell cycle and apoptosis (Fig. 4H).

YAP knockdown enhances the antitumor activity of dioscin. To further understand the role of YAP in mediating the suppressive effects of dioscin on SCC15 cells, SCC15 cells were transduced with sh YAP or sh NC and then treated with $1 \mu \mathrm{M}$ dioscin. Flow cytometry was performed to assess alterations in cell cycle distribution and apoptosis. Both YAP knockdown and dioscin treatment led to a decrease of cells in $\mathrm{G}_{2} / \mathrm{M}$ phase, and the combination of these interventions augmented this effect $\left(\mathrm{G}_{2} / \mathrm{M}\right.$ phase cells: sh $\mathrm{NC}$, $11.770 \pm 0.0880 \%$; sh NC + dioscin, $11.000 \pm 0.152 \%$; sh YAP, $10.300 \pm 0.152 \%$; and sh YAP + dioscin, $6.263 \pm 0.489 \%$ ) (Fig. 5A and B). Moreover, compared with the sh NC group $(19.860 \pm 0.474 \%)$, the proportion of apoptotic cells was increased following dioscin treatment $(21.600 \pm 0.462 \%)$ (not statistically significant) or YAP knockdown $(22.010 \pm 0.353 \%)$, and the combination of these two interventions was synergistic (27.020 $\pm 0.277 \%$ ) (Fig. 5C and D). Subsequently, SCC15 cell proliferation was evaluated by performing EdU incorporation (Fig. 5E and F) and CCK-8 (Fig. 5G) assays. Compared with the sh NC group, both dioscin and YAP knockdown significantly decreased cell proliferation. In addition, the combination of dioscin treatment and YAP knockdown resulted in further inhibition of cell proliferation compared with either intervention alone, as determined by flow cytometry, EdU staining, western blotting and CCK-8 assay at $24 \mathrm{~h}$.

Subsequently, the expression levels of YAP, cyclin D1, BCL-2 and BAX were measured. Similarly, the combination of dioscin treatment and YAP knockdown led to more notable suppressive effects on protein expression compared with either intervention alone. However, the expression levels of the proapoptotic protein BAX displayed the opposite trends (Fig. 5H). 
A

$$
0 \mu \mathrm{M} \quad 0.5 \mu \mathrm{M} 1 \mu \mathrm{M} \quad 2 \mu \mathrm{M}
$$

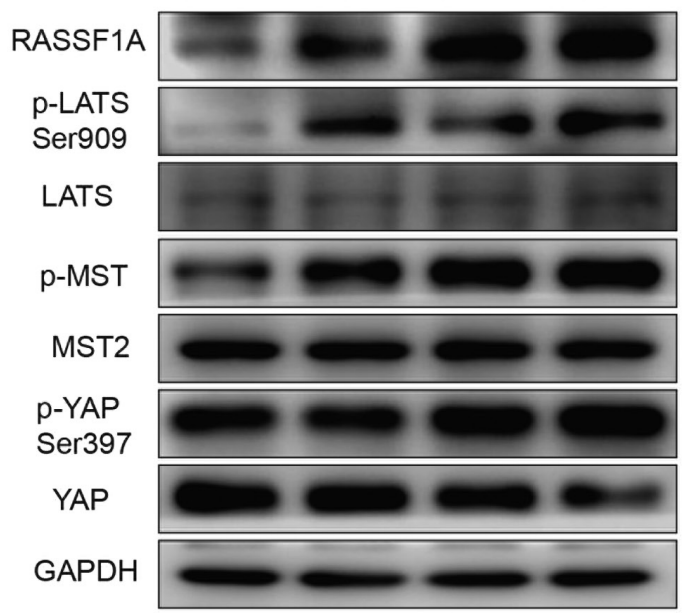

C

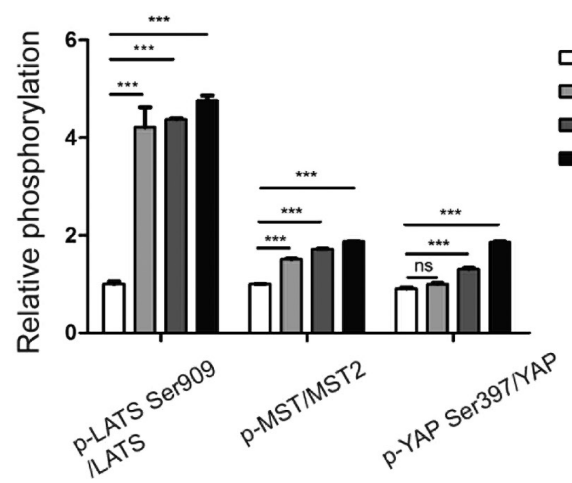

$\mathrm{E}$

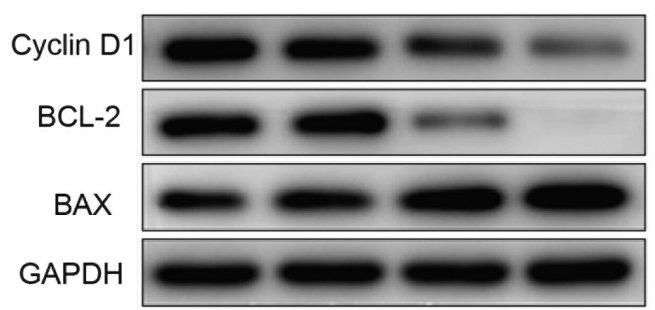

G

$$
0 \mu \mathrm{M} \quad 0.5 \mu \mathrm{M} \quad 1 \mu \mathrm{M} \quad 2 \mu \mathrm{M}
$$

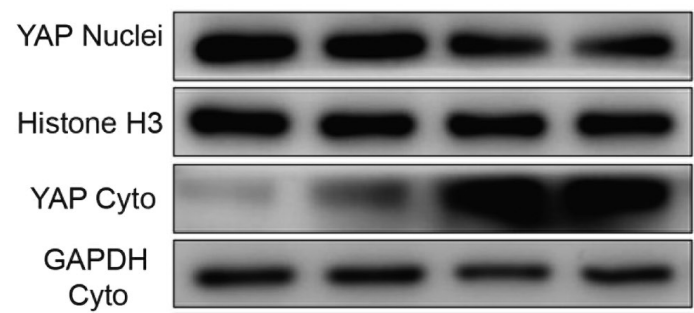

B

\section{$0 \mathrm{~h} \quad 2 \mathrm{~h} \quad 4 \mathrm{~h} \quad 8 \mathrm{~h}$}

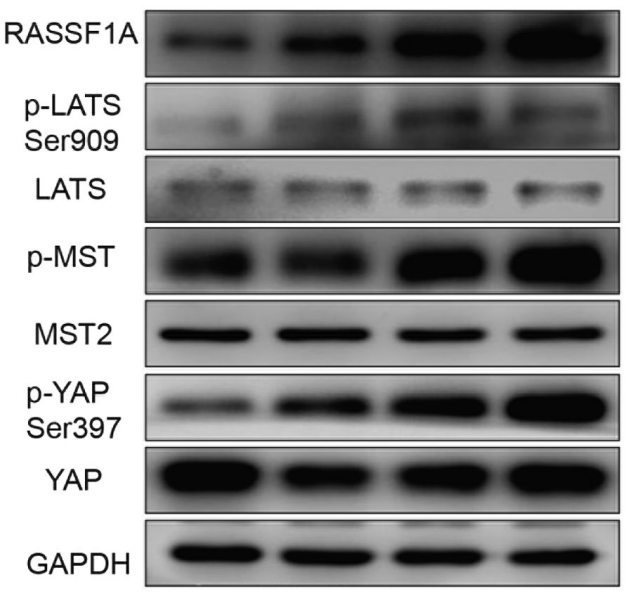

D

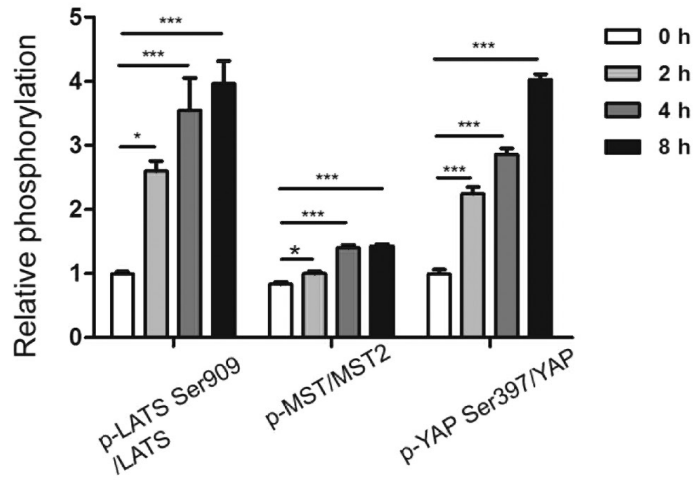

\section{$\mathrm{F} \quad 0 \mathrm{~h} \quad 2 \mathrm{~h} \quad 4 \mathrm{~h} \quad 8 \mathrm{~h}$}

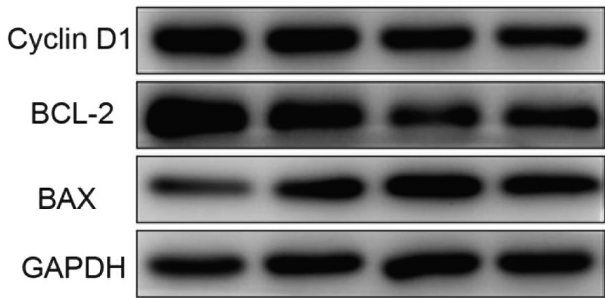

$\mathrm{H}$ Input IgG ip: MST2

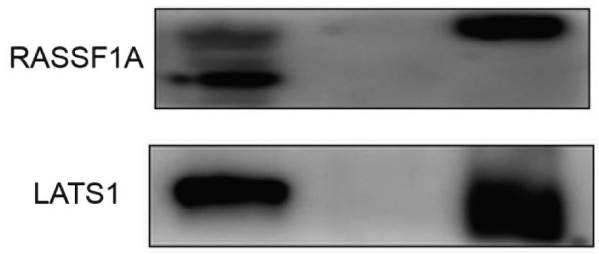

Figure 3. Dioscin inhibits SCC15 cell proliferation via inactivating the Hippo signaling pathway. Following treatment with (A) $0,0.5,1$ or $2 \mu \mathrm{M}$ dioscin for $24 \mathrm{~h}$ or (B) $1 \mu \mathrm{M}$ dioscin for 0,2, 4 or $8 \mathrm{~h}$, Hippo signaling pathway-related protein expression levels were measured via western blotting. Hippo signaling pathway-related protein expression levels were semi-quantified in SCC15 cells treated with (C) $0,0.5,1$ or $2 \mu \mathrm{M}$ dioscin for $24 \mathrm{~h}$ or (D) $1 \mu \mathrm{M}$ dioscin for $0,2,4$ or $8 \mathrm{~h}$. Following treatment with (E) $0,0.5,1$ or $2 \mu \mathrm{M}$ dioscin for $24 \mathrm{~h}$ or (F) $1 \mu \mathrm{M}$ dioscin for $0,2,4$ or $8 \mathrm{~h}$, cell cycle and apoptosis-related protein expression levels were determined via western blotting. (G) Following treatment with $0,0.5,1$ or $2 \mu \mathrm{M}$ dioscin for $24 \mathrm{~h}$, nuclear and cytoplasmic proteins were extracted and detected via western blotting. (H) Following treatment with $1 \mu \mathrm{M}$ dioscin for $24 \mathrm{~h}$, MST2 immunoprecipitation was detected via coprecipitation with RASSF1A and LATS1 followed by western blotting analysis. Data are presented as the mean \pm SD of three independent experiments. "P<0.05 and ${ }^{* * *} \mathrm{P}<0.001$. RASSF1A, Ras association domain-containing protein 1A; p, phosphorylated; LATS, large tumor suppressor kinase; MST, macrophage stimulating; YAP, yes-associated protein; Cyto, cytoplasmic; ip, immunoprecipitation. 

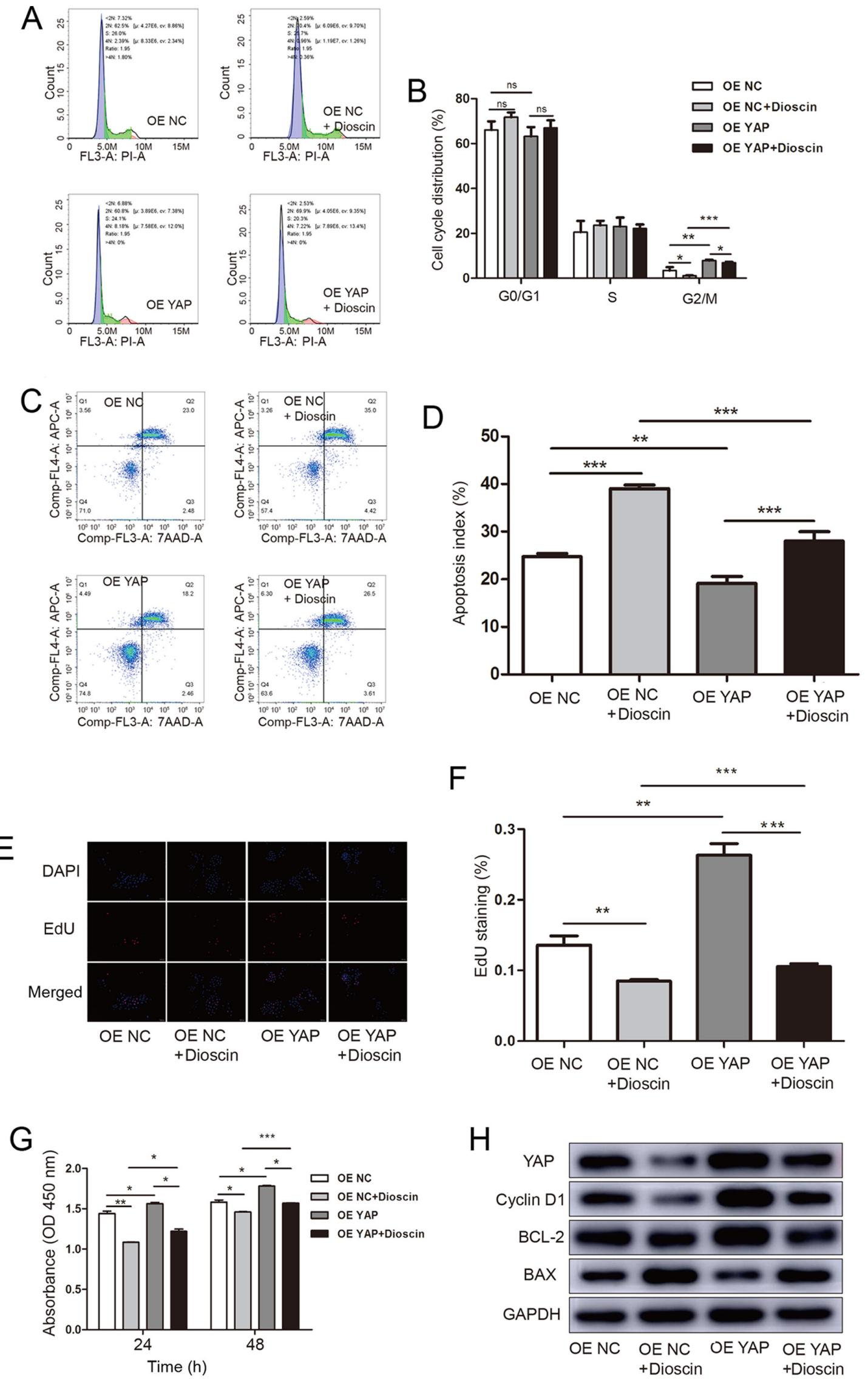

Figure 4. YAP OE reverses dioscin-mediated inhibition of cell proliferation. Effects of YAP OE and dioscin treatment on the cell cycle distribution were (A) determined via flow cytometry and (B) quantified. Effects of YAP OE and dioscin treatment on cell apoptosis were (C) determined via flow cytometry and (D) quantified. Cell proliferation was (E) detected by performing EdU staining (magnification, x200) and (F) quantified. (G) Cell proliferation was also assessed by performing Cell Counting Kit-8 assays. (H) Protein expression levels were measured via western blotting. Data are presented as the mean \pm SD of three independent experiments. ${ }^{*} \mathrm{P}<0.05,{ }^{* *} \mathrm{P}<0.01$ and ${ }^{* * *} \mathrm{P}<0.001$. YAP, yes-associated protein; OE, overexpression; NC, negative control; OD, optical density; ns, not significant; EdU, 5-ethynyl-2'-deoxyuridine. 
A
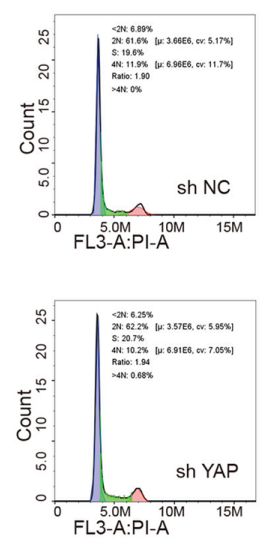

C
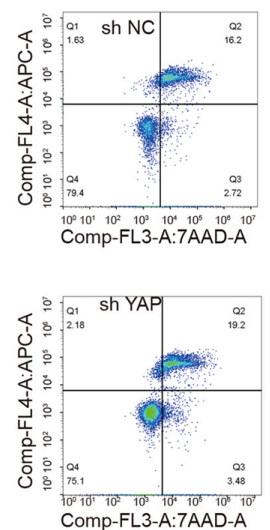

$E$

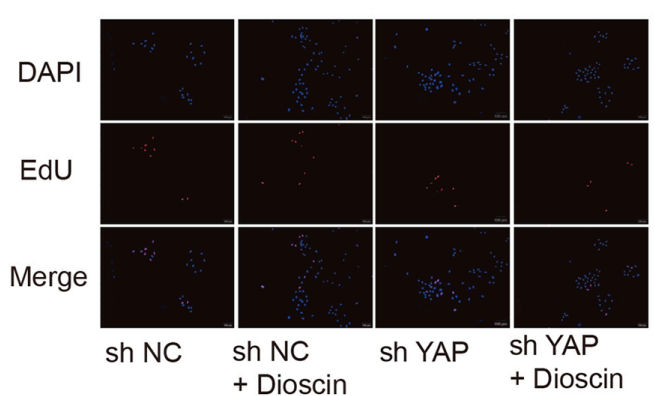

$\mathrm{G}$
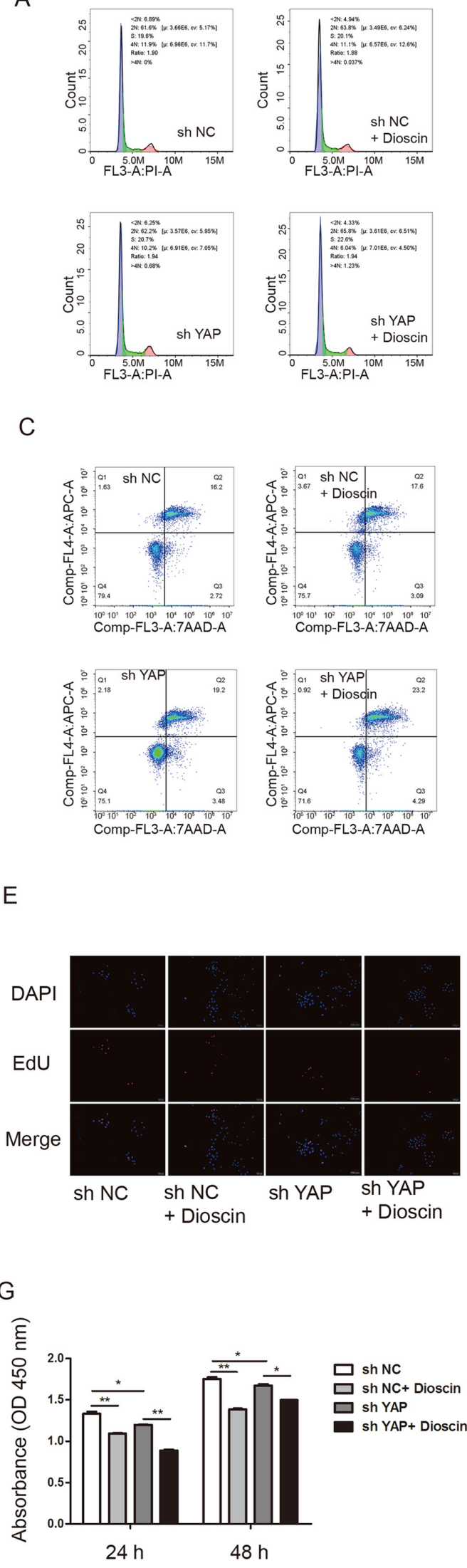

B

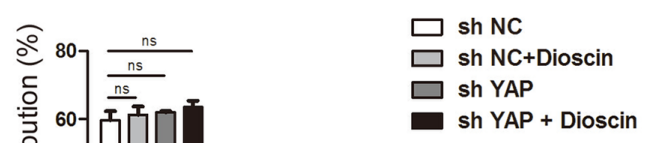

D

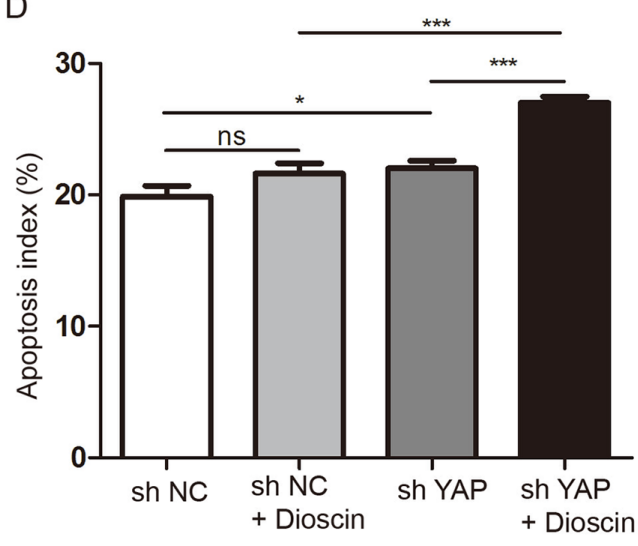

$\mathrm{F}$

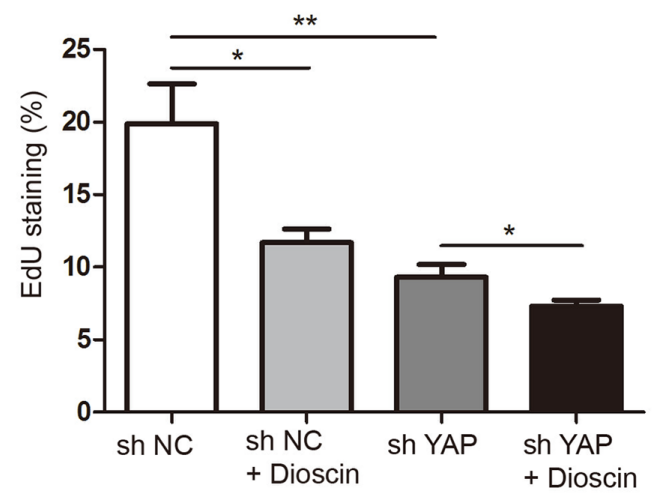

$\mathrm{H}$

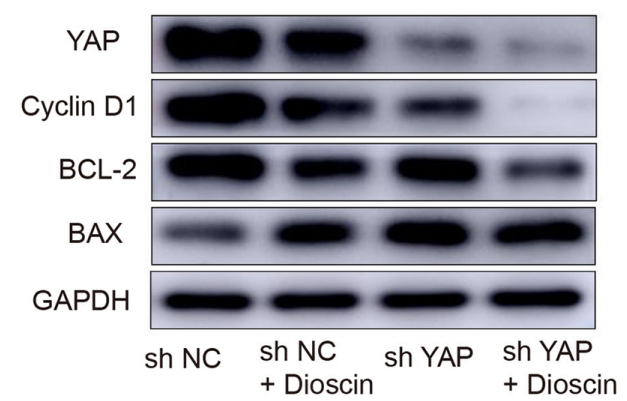

Figure 5. YAP knockdown enhances dioscin-induced inhibition of cell proliferation. Effects of YAP knockdown and dioscin treatment on SCC15 cell cycle distribution were (A) determined via flow cytometry and (B) quantified. Effects of YAP knockdown and dioscin treatment on SCC15 cell apoptosis were (C) determined via flow cytometry and (D) quantified. Cell proliferation was (E) determined by performing EdU staining (magnification, x200) and (F) quantified. (G) Cell proliferation was also assessed by performing Cell Counting Kit-8 assays. (H) Protein expression levels were determined via western blotting. Data are presented as the mean $\pm \mathrm{SD}$ of three independent experiments. ${ }^{*} \mathrm{P}<0.05,{ }^{* *} \mathrm{P}<0.01$ and ${ }^{* * * *} \mathrm{P}<0.001$. YAP, yes-associated protein; sh, short hairpin; NC, negative control; APC, allophycocyanin; OD, optical density; EdU, 5-ethynyl-2'-deoxyuridine. 


\section{Discussion}

OSCC is one of the most common and malignant tumors in the oral and maxillofacial regions; however, following systemic treatment, the prognosis of patients with OSCC is still poor (25). In addition to the health and functional abnormalities that typically result from tumors, OSCC often affects the appearance of patients, leading to a heavy psychological burden (26).

Dioscin is a natural steroidal saponin that can be extracted from various traditional Chinese medicines, including Dioscorea . Dioscin has been reported to exert a variety of biological activities, including protection against liver damage (27) and anti-inflammatory activity (28). Moreover, dioscin may produce anticancer effects on various types of cancer cells (29-32). Previous studies have indicated that dioscin induced cervical carcinoma cell apoptosis (33) and suppressed ovarian cancer cell viability (34). The present study demonstrated that, compared with the control group, dioscin resulted in cell cycle arrest and increased apoptosis, which was consistent with a previous study that indicated that dioscin protected against cancer progression (35). The present study also assessed cell cycle- and apoptosis-related protein expression levels, including cyclin D1, BCL-2 and BAX. The alterations in protein expression levels were consistent with the alterations in biological activities.

YAP is the hub protein in the Hippo signaling pathway (36). Previous studies have demonstrated that the Hippo signaling pathway is inactivated and YAP protein expression is increased in numerous types of cancer, including cervical cancer, urothelial cell carcinoma and oral squamous cell carcinoma (37-39). Direct inhibition of the YAP oncoprotein is an anticancer therapeutic strategy (40). A previous study reported that dioscin downregulated the expression of tafazzin, a homolog protein of YAP, in hepatocellular carcinoma; however, alterations in YAP expression were not investigated (41). The present study demonstrated that, compared with the control group, dioscin notably deactivated YAP protein expression by increasing its phosphorylation, and nuclear YAP accumulation was markedly decreased following dioscin treatment. Therefore, it was hypothesized that dioscin inhibited OSCC cell viability by downregulating YAP expression. To further investigate whether the effects of dioscin on the biological characteristics of OSCC cells were mediated via YAP, YAP expression was altered in OSCC cells via LV transduction. YAP overexpression and knockdown reduced and enhanced dioscin-induced antitumor effects, respectively.

RASSF1A is one of the most commonly inactivated tumor suppressor genes in sporadic human malignant tumors (42). RASSF1A activation is an important factor in the pathogenesis and progression of solid tumors $(43,44)$. A previous study reported that dioscin demethylated the RASSF1A gene in bladder cancer cells, thus inhibiting cancer cell proliferation (21). The present study demonstrated that RASSF1A protein expression levels were increased by dioscin treatment in a concentration- and time-dependent manner compared with the control group. Increases in RASSF1A expression provided a potential explanation for the inhibitory effects of dioscin on OSCC cell proliferation. A previous study demonstrated that ATM serine/threonine kinase directly phosphorylated the Ser131 site in RASSF1A, activating MST2 and LATS1 (22), which then phosphorylated YAP and induced cell apoptosis.
The results of the present study demonstrated that dioscin treatment enhanced the binding of MST2 with RASSF1A and LATS1, which could be explained by the augmentation of YAP phosphorylation.

To conclude, the present study demonstrated that dioscin resulted in OSCC cell cycle arrest and apoptosis, which involved the RASSF1A/MST2/YAP signaling axis. The present study indicated that dioscin may serve as a useful therapeutic agent for OSCC or other types of tumors.

\section{Acknowledgements}

Not applicable.

\section{Funding}

The present study was supported by the Shandong Provincial Natural Science Foundation (grant no. ZR2018MH018), China Postdoctoral Science Foundation (grant no. 2017M610432) and Young Scholars Program of Shandong University (grant no. 2015WLJH53).

\section{Availability of data and materials}

The datasets used and/or analyzed during the current study are available from the corresponding author on reasonable request.

\section{Authors' contributions}

HT and XC performed the experiments, analyzed the data, prepared the figures and tables, and wrote the manuscript. YZ and YWe assisted in the data collection and analyses. YWa and $\mathrm{XF}$ assisted in data analyses. HT and XC confirm the authenticity of all the raw data. WG was involved in designing the experiments and drafting the manuscript. YWe agreed to be accountable for all aspects of the work, supervised the work, edited the manuscript and gave final approval of the version to be published. All authors read and approved the final manuscript.

\section{Ethics approval and consent to participate}

Not applicable.

\section{Patient consent for publication}

Not applicable.

\section{Competing interests}

The authors declare that they have no competing interests.

\section{References}

1. Omar E: Current concepts and future of noninvasive procedures for diagnosing oral squamous cell carcinoma - a systematic review. Head Face Med 11: 6, 2015.

2. Ferlay J, Soerjomataram I, Dikshit R, Eser S, Mathers C, Rebelo M, Parkin DM, Forman D and Bray F: Cancer incidence and mortality worldwide: Sources, methods and major patterns in GLOBOCAN 2012. Int J Cancer 136: E359-E386, 2015.

3. Haddad RI and Shin DM: Recent advances in head and neck cancer. N Engl J Med 359: 1143-1154, 2008. 
4. Ferris RL, Blumenschein G Jr, Fayette J, Guigay J, Colevas AD, Licitra L, Harrington K, Kasper S, Vokes EE, Even C, et al: Nivolumab for recurrent squamous-cell carcinoma of the head and neck. N Engl J Med 375: 1856-1867, 2016.

5. Siegel RL, Miller KD and Jemal A: Cancer statistics, 2019. CA Cancer J Clin 69: 7-34, 2019.

6. Chestnut C, Subramaniam D, Dandawate P, Padhye S, Taylor J III, Weir S and Anant S: Targeting major signaling pathways of bladder cancer with phytochemicals: A review. Nutr Cancer 11: 1-23, 2020.

7. Khan T, Ali M, Khan A, Nisar P, Jan SA, Afridi S and Shinwari ZK: Anticancer plants: A review of the active phytochemicals, applications in animal models, and regulatory aspects Biomolecules 10: 47, 2019.

8. Kalailingam P, Kannaian B, Tamilmani E and Kaliaperumal R: Efficacy of natural diosgenin on cardiovascular risk, insulin secretion, and beta cells in streptozotocin (STZ)-induced diabetic rats. Phytomedicine 21: 1154-1161, 2014.

9. Zheng L, Yin L, Xu L, Qi Y, Li H, Xu Y, Han X, Liu K and Peng J: Protective effect of dioscin against thioacetamide-induced acute liver injury via FXR/AMPK signaling pathway in vivo. Biomed Pharmacother 97: 481-488, 2018

10. Zhang Y, Xu Y, Qi Y, Xu L, Song S, Yin L, Tao X, Zhen Y, Han X, Ma X, et al: Protective effects of dioscin against doxorubicin-induced nephrotoxicity via adjusting FXR-mediated oxidative stress and inflammation. Toxicology 378: 53-64, 2017.

11. Zhao L, Tao X, Qi Y, Xu L, Yin L and Peng J: Protective effect of dioscin against doxorubicin-induced cardiotoxicity via adjusting microRNA-140-5p-mediated myocardial oxidative stress. Redox Biology 16: 189-198, 2018.

12. Zhang Y, Tao X, Yin L, Xu L, Xu Y, Qi Y, Han X, Song S, Zhao Y, Lin Y, et al: Protective effects of dioscin against cisplatin-induced nephrotoxicity via the microRNA-34a/sirtuin 1 signalling pathway. Br J Pharmacol 174: 2512-2527, 2017.

13. Mao Z, Han X, Chen D, Xu Y, Xu L, Yin L, Sun H, Qi Y, Fang L, Liu K and Peng J: Potent effects of dioscin against hepatocellular carcinoma through regulating TP53-induced glycolysis and apoptosis regulator (TIGAR)-mediated apoptosis, autophagy, and DNA damage. Br J Pharmacol 176: 919-937, 2019.

14. Si L, Zheng L, Xu L, Yin L, Han X, Qi Y, Xu Y, Wang C and Peng J: Dioscin suppresses human laryngeal cancer cells growth via induction of cell-cycle arrest and MAPK-mediated mitochondrial-derived apoptosis and inhibition of tumor invasion. Eur J Pharmacol 774: 105-117, 2016

15. Wei Y, Xu Y, Han X, Qi Y, Xu L, Xu Y, Yin L, Sun H, Liu K and Peng J: Anti-cancer effects of dioscin on three kinds of human lung cancer cell lines through inducing DNA damage and activating mitochondrial signal pathway. Food Chem Toxicol 59: $118-128,2013$

16. Guo C,Zhang X and Pfeifer GP: The tumor suppressor RASSF1A prevents dephosphorylation of the mammalian STE20-like kinases MST1 and MST2. J Biol Chem 286: 6253-6261, 2011.

17. Huang J, Wu S, Barrera J, Matthews K and Pan D: The Hippo signaling pathway coordinately regulates cell proliferation and apoptosis by inactivating Yorkie, the Drosophila Homolog of YAP. Cell 122: 421-434, 2005.

18. Harvey KF, Zhang $X$ and Thomas DM: The Hippo pathway and human cancer. Nat Rev Cancer 13: 246-257, 2013.

19. Dammann R, Li C, Yoon JH, Chin PL, Bates S and Pfeifer GP: Epigenetic inactivation of a RAS association domain family protein from the lung tumour suppressor locus 3p21.3. Nat Genet 25: 315-319, 2000 .

20. Agathanggelou A, Cooper WN and Latif F: Role of the Ras-association domain family 1 tumor suppressor gene in human cancers. Cancer Res 65: 3497-508, 2005.

21. Zhou Q, Song W and Xiao W: Dioscin induces demethylation of DAPK-1 and RASSF-1alpha genes via the antioxidant capacity, resulting in apoptosis of bladder cancer T24 cells. EXCLI J 16: $101-112,2017$

22. Hamilton G, Yee KS, Scrace S and O'Neill E: ATM regulates a RASSF1A-dependent DNA damage response. Curr Biol 19: 2020-2025, 2009

23. Xu G, Zhou X, Xing J, Xiao Y, Jin B, Sun L, Yang H, Du S, Xu H and Mao Y: Identification of RASSF1A promoter hypermethylation as a biomarker for hepatocellular carcinoma. Cancer Cell Int 20: 547,2020

24. Guo C, Tommasi S, Liu L, Yee JK, Dammann R and Pfeifer GP. RASSF1A is part of a complex similar to the Drosophila Hippo/ Salvador/Lats tumor-suppressor network. Curr Biol 17: 700-705, 2007.
25. Schwam ZG and Judson BL: Improved prognosis for patients with oral cavity squamous cell carcinoma: Analysis of the National Cancer Database 1998-2006. Oral Oncol 52: 45-51, 2016.

26. Metzger K, Moratin J, Horn D, Pilz M, Ristow O, Hoffmann J, Freier K, Engel M and Freudlsperger C: Treatment delay in early-stage oral squamous cell carcinoma and its relation to survival. J Craniomaxillofac Surg: Feb 12, 2021 (Epub ahead of print). doi: 10.1016/j.jcms.2021.02.007.

27. Lu B, Xu Y, Xu L, Cong X, Yin L, Li H and Peng J: Mechanism investigation of dioscin against $\mathrm{CCl} 4$-induced acute liver damage in mice. Environ Toxicol Pharmacol 34: 127-135, 2012.

28. Wu S, Xu H, Peng J, Wang C, Jin Y, Liu K, Sun H and Qin J: Potent anti-inflammatory effect of dioscin mediated by suppression of TNF- $\alpha$-induced VCAM-1, ICAM-1and EL expression via the NF-кB pathway. Biochimie 110: 62-72, 2015.

29. Hsieh MJ, Tsai TL, Hsieh YS, Wang CJ and Chiou HL: Erratum to: Dioscin-induced autophagy mitigates cell apoptosis through modulation of PI3K/Akt and ERK and JNK signaling pathways in human lung cancer cell lines. Arch Toxicol 91: 2495-2496, 2017.

30. Gao LL, Li FR, Jiao P, Yang MF, Zhou XJ, Si YH, Jiang WJ and Zheng TT: Paris chinensis dioscin induces G2/M cell cycle arrest and apoptosis in human gastric cancer SGC-7901 cells. World J Gastroenterol 17: 4389-4395, 2011.

31. Song X, Wang Z, Liang H, Zhang W, Ye Y, Li H, Hu Y, Zhang Y, Weng H, Lu J, et al: Dioscin induces gallbladder cancer apoptosis by inhibiting ROS-Mediated PI3K/AKT signalling. Int J Biol Sci 13: 782-793, 2017.

32. Hsu WH, Lee BH and Pan TM: Effects of red mold dioscorea on oral carcinogenesis in DMBA-induced hamster animal model. Food Chem Toxicol 49: 1292-1297, 2011.

33. Zhao X, Tao X, Xu L, Yin L, Qi Y, Xu Y, Han X and Peng J: Dioscin induces apoptosis in human cervical carcinoma HeLa and $\mathrm{SiHa}$ cells through ROS-Mediated DNA damage and the mitochondrial signaling pathway. Molecules 21: 730, 2016.

34. Guo $X$ and Ding X: Dioscin suppresses the viability of ovarian cancer cells by regulating the VEGFR2 and PI3K/AKT/MAPK signaling pathways. Oncol Lett 15: 9537-9542, 2018

35. Si L, Xu L, Yin L, Qi Y, Han X, Xu Y, Zhao Y, Liu K and Peng J: Potent effects of dioscin against pancreatic cancer via miR-149-3P-mediated inhibition of the Akt1 signalling pathway. Br J Pharmacol 174: 553-568, 2017.

36. Hansen CG, Moroishi T and Guan KL: YAP and TAZ: A nexus for Hippo signaling and beyond. Trends Cell Biol 25: 499-513, 2015.

37. He C, Mao D, Hua G, Lv X, Chen X, Angeletti PC, Dong J, Remmenga SW, Rodabaugh KJ, Zhou J, et al: The Hippo/YAP pathway interacts with EGFR signaling and HPV oncoproteins to regulate cervical cancer progression. EMBO Mol Med 7: 1426-1449, 2015.

38. Ciamporcero E, Shen H, Ramakrishnan S, Yu Ku S, Chintala S, Shen L, Adelaiye R, Miles KM, Ullio C, Pizzimenti S, et al: YAP activation protects urothelial cell carcinoma from treatment-induced DNA damage. Oncogene 35: 1541-1553, 2016.

39. Chen X, Gu W, Wang Q, Fu X, Wang Y, Xu X and Wen Y: C-MYC and BCL-2 mediate YAP-regulated tumorigenesis in OSCC. Oncotarget 9: 668-679, 2018.

40. Bae JS, Kim SM and Lee H: The Hippo signaling pathway provides novel anti-cancer drug targets. Oncotarget 8: 16084-16098, 2017.

41. Chen Z, Xu J, Wu Y, Lei S, Liu H, Meng Q and Xia Z: Diosgenin inhibited the expression of TAZ in hepatocellular carcinoma. Biochem Biophys Res Commun 503: 1181-1185, 2018.

42. Grawenda AM and O'Neill E: Clinical utility of RASSF1A methylation in human malignancies. Br J Cancer 113: 372-381, 2015.

43. Zhou SL, Cui J, Fan ZM, Li XM, Li JL, Liu BC, Zhang DY, Liu HY, Zhao XK, Song X, et al: Polymorphism of A133S and promoter hypermethylation in Ras association domain family $1 \mathrm{~A}$ gene (RASSF1A) is associated with risk of esophageal and gastric cardia cancers in Chinese population from high incidence area in northern China. BMC Cancer 13: 259, 2013.

44. Klacz J, Wierzbicki PM, Wronska A, Rybarczyk A, Stanislawowski M, Slebioda T, Olejniczak A, Matuszewski M and Kmiec Z: Decreased expression of RASSF1A tumor suppressor gene is associated with worse prognosis in clear cell renal cell carcinoma. Int. J Oncol 48: 55-66, 2016.

This work is licensed under a Creative Commons Attribution-NonCommercial-NoDerivatives 4.0 International (CC BY-NC-ND 4.0) License. 